megative result. For some time after this the attacks of hæmaturia recurred at intervals of about six months, and eight years ago, during an especially severe attack, the man was admitted into the Birmingham General Hospital under the care of Mr. Heaton, and as the bladder was distended up to the umbilicus with blood-clot suprapubic cystotomy was performed; but no source of bleeding could be found in the bladder. There was no hæmaturia for three months after this, but then the attacks began to increase in frequency and the patient was admitted into the same hospital as on the first occasion and his right kidney was explored, but also with a negative result. The hæmaturia continued and four years ago the left kidney was again explored in the same hospital, but with a similar result.

The patient was readmitted into the Birmingham General Hospital two and a half years ago and the bladder was examined with the cystoscope but no source of the bleeding could be found. Since that time he had had almost constant severe pain in the left loin and had passed blood every day. On Jan. 1st, 1902, he was again admitted into the Birmingham General Hospital. He was very anæmic, was passing a large quantity of blood each time he micturated, and on bimanual examination his left kidney was felt to be much enlarged. He also complained of constant aching pain in the region of the left kidney. As previous explorations of the kidney had been without result it was decided that the best course to adopt would be to perform lumbar nephrectomy. Accordingly, on Jan. 10th. this was done by $\mathrm{Mr}$. Gamgee, the operation proving to be difficult owing to the very dense adhesions resulting from the two previous operations. The patient made an uneventful recovery and is at the present time in good health and free from hæmaturia.

The kidney after removal was found to be of about twice the normal size of the organ. The renal pelvis was dilated and completely filled with a diffuse villous growth, which was growing from the whole of the lining wall of the pelvis, there being apparently no part of the wall free from growth which, however, did not extend down the ureter. The kidney substance had completely disappeared, only a fibrous walled sac remaining. The inner lining of the sac wall was over about two-thirds of its area covered with villous growth, which did not fill the sac to the same extent that the pelvis was filled. On microscopic examination the growth was found to be a non-malignant villous papilloma.

Remarks by Mr. GAMGEE. The existence of a villous papilloma in the pelvis of the kidney gives rise, in the first instance, to symptoms strikingly like those caused by the presence of a similar tumour in the bladder-namely, intermittent profuse hæmaturia with intervals of freedom from symptoms. In this case at the time of operation the enlargement of the kidney had given the first definite information as to the source of the bleeding, and it was felt that nephrectomy, and not simply another exploration, would be the best treatment. Notwithstanding that the growth had been in existence for such a long time, the interior of the ureter was apparently free from growth, though it is a well-known fact that such a growth occurring in the pelvis of the kidney may extend down the ureter into the bladder. The irritation caused by the presence of a calculus may give rise to a villous papilloma in the renal pelvis, but in this instance it does not seem possible to assign any direct cause. The case came under my care owing to the absence through illness of Mr. Heaton, to whom I am indebted for permission to use the notes relating to the past history of the patient and for valuable advice concerning the treatment of the case.

\section{CIVIL HOSPITAL, HALFA, SOUDAN.} A CASE OF LUMBAR HERNIA.

(Under the care of Mr. A. WEBB Jones.)

LUMBAR hernia is a hernia through, or in the neighbourhood of, the triangle of Petit. The size of this triangle varies greatly in different persons. It consists in an interval left between the latissimus dorsi and the external oblique muscles and sometimes these overlap at their attachment to the iliac crest, so that then no triangle of Petit exists. In many cases of lumbar thernia an abscess has weakened the abdominal wall at this spot; in others there is a clear history of local injury.
These hernix have a great tendency to strangulation ${ }^{\mathbf{l}}$ and in the first case of which we have any record the patient died from the strangulation in $1731 .^{2}$ Ravaton $^{3}$ in 1738 operated successfully on a strangulated lumbar hernia. Mr. Edmund Owen's ${ }^{4}$ case was the first in which a radical cure was performed of a hernia of this form and below is recorded a very successful radical cure of a large lumbar hernia.

In a fairly typical case of lumbar hernia the patient was a well-developed male Soudanese, aged about 45 years. He had noticed the swelling for some four or five years and had lately had considerable trouble from local pain and tenderness, with constipation and dyspepsia. The patient could not recall any special blow or strain to which one might attribute the protrusion, but of course any such details from a native of his mental calibre would be of little value. For some days previous to the operation his evening temperature ranged between $99^{\circ}$ and $100^{\circ} \mathrm{F}$. On examination the right lumbar region presented a large fluctuating tumour, roughly oval in shape but of slightly irregular outline. It extended from the level of the iliac crest inwards and upwards towards the spine and overlapped the lower three or four ribs. The mass gave one the impressicn that it was to a great extent composed of fat, but on

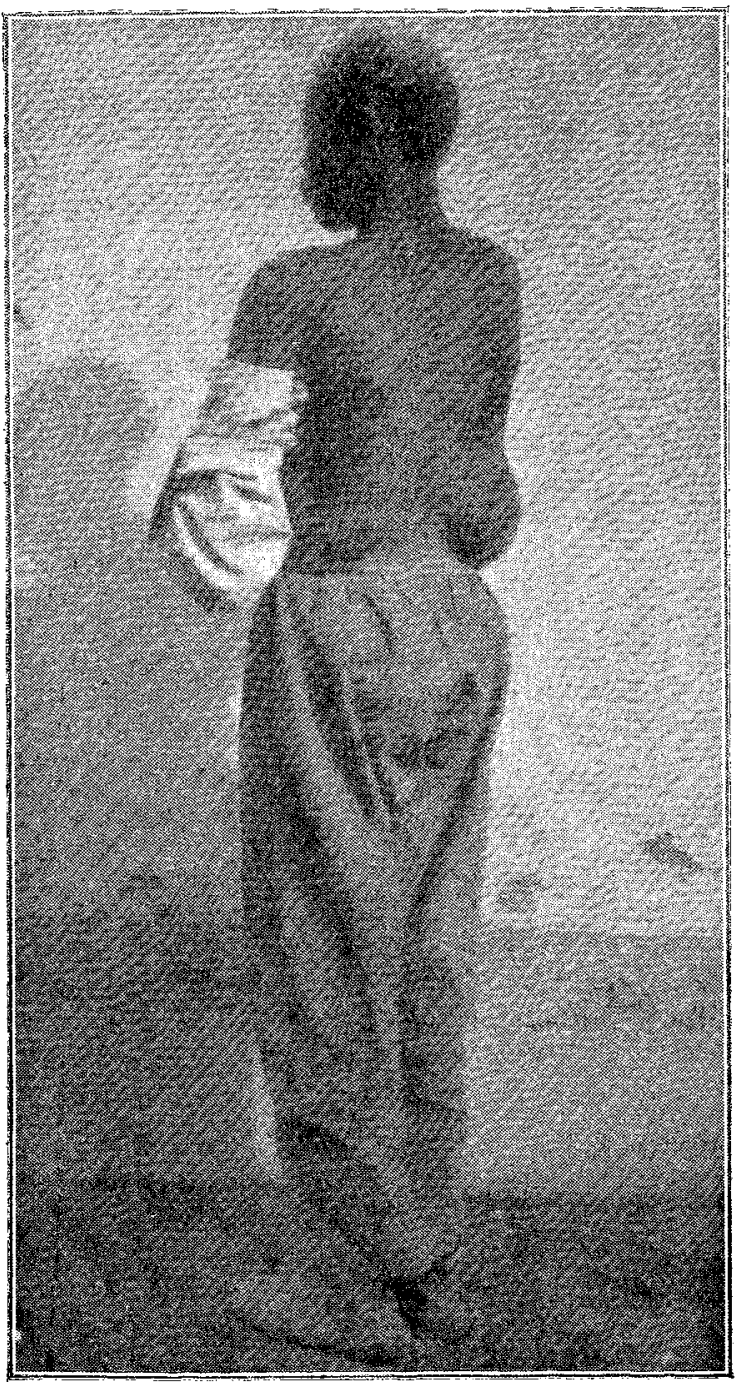

Lumbar hernia

reduction-which was easily effected through Petit's triangle -a distinct gurgle was to be felt. The impulse on coughing was very well marked. Over the site of Petit's triangle was a broad scar about two inches long. Mr. Jones was of opinion that this was the result of a mere superficial cut and had no causal relation to the hernia. (It should be mentioned that the habit of -making skin cuts with a razor, either for cosmetic or medicinal effect, is very common amongst the

1 Macready, THE LANCET, Nov. 8th, 1890, p. 963.

2 Garangeot, Traité des Opérations, p. 369

3 Traité des Plaies d'Armes de Feu, 1750

4 THE LA ICET, May 5th, 1888 , p. 883 . 
Soudanese.) In the left lumbar region there was a slight undue fulness, apparently consisting of fat (perhaps subperitoneal in origin and the forerunner of a hernia), but this gave rise to no symptoms. The patient also presented a left inguinal hernia of moderate dimensions.

An operation with a view to a radical cure was commenced by an oblique incision downwards and forwards over the site of the triangle. After retracting the edges of the external oblique and latissimus dorsi the lumbar fascia was incised. Here a large lobulated mass of adipose tissue presented. The depths of the opening appeared to be divided, so to say, into an upper and lower division by some fibrous bands, above and below which portions of the fatty tissue protruded. Traction on this tissue brought into the wound the ascending colon, which appeared somewhat dilated and thickened. After removing the fat and reducing the colon the edges of the latissimus dorsi and external oblique were united with silkworm-gut and the wound was closed. Primary union was obtained and recovery was uneventful.

Remarks by Mr JoNes. - Herniæ in the region of Petit's triangle, other than those following abscess, are so uncommon that an account of a fresh case may prove of interest. Looking at the somewhat imperfect records of 25 old cases 5 one is able to generalise on the common features of this rare condition. With regard to etiology the sexes are almost equally represented, whilst the majority of the hernia, appear for the first time at middle age. Three of the 25 cases occurred in infants, but one of these followed an old psoas abscess. By far the gravest characteristic, however, of this variety of hernia is its very marked tendency to pro. duce symptoms of local pain, constipation, or even strangulation. Of the 25 cases referred to above no less than four became strangulated, five are said to have been from time to time the cause of vomiting, colic, or constipation, whilst six only are stated definitely to have given no trouble; the rest are without details. One case was bilateral and associated with an inguinal hernia. In two instances the diagnosis was at fault and the bowel was damaged, the surgeon being under the impression that he was incising an abscess.

The question of the existence or non-existence of a sac in these cases is a matter of great interest. In Dr. G. H. Hume's ${ }^{6}$ case (operated on for strangulation) a sac is mentioned, but no post-mortem examination was made. In Mr. E. Owen's ${ }^{7}$ case (radical cure in a small child who developed a hernia after an old psoas abscess) the point was not investigated. In the case dissected by Mr. J. Hutchinson, jun., ${ }^{\checkmark}$ no sac was discovered, but he suggests that the elasticity of the peritoneum together with its loose attachment in this region might allow of some protrusion through the opening witb intra-abdominal strain, the peritoneum recoiling with the reduction of the hernia to resume its normal position. I am of opinion that probably such may have been the case to some extent in my own patient. The protrusion of the fatty tissue and colon would doubtless account for a large bulk of the tumour seen on external examination, but $I$ think that a residue would still remain unaccounted for. The fibrous bands crossing the depths of the triangle are also worthy of note. Dr. Hume, in his case of strangulation attributes the constricting agency to similar structures. However, his case did not absolutely correspond to the anatomical site of Petit's triangle, so the parallel may not be insisted on too closely.

5 Mastin: Annals of Surgery, 1890.
6 Brit. Med. Jour., 1889 , vol. ii., p. 73.
7 Loc cit.

Brit. Med. Jour., 1889, vol. ii , p. 71.

Vaccrnation Fens.-At the meeting of the Hambledon (Surrey) board of guardians held on Sept. 4th the vaccination committee recommended that fresh contracts should be made for public vaccinators and that the fees should be modified in accordance with the following scalenamely, that a fee of $2 s .6 d$. be paid for the revaccination of all persons at boarding-schools, hotels, boarding-houses, and all similar public institutions and places of business. The clerk said that many of the people who were vaccinated at their homes might well go to the surgery to be vaccinated for $2 s .6 d$. The recommendation was adopted. The clerk suggested that the scale should be submitted to the public vaccinators for their observations before sending to the Local Government Board. This course was adopted.

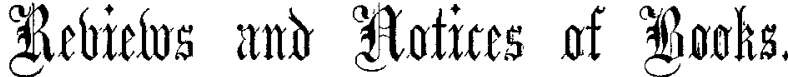

Diseases of the Intestines. By JoHN C. Hemmeter, M.D.

Philos. D., Professor in the Medical Department of the University of Maryland ; Consultant to the University Hospital and Director of the Clinical Laboratory. In Two

Volumes. Volume I. With many Original Illustrations. London: Rebman, Limited. Pp. 742. Price 50s. (com. plete work).

THIs work promises to be one of the most complete monographs on diseases of the intestines yet published. The first volume is concerned with the anatomy and physiology of the intestives, the chief bacteria which infect the tract, methods of diagnosis, therapy and materia medica of intestinal diseases, the symptomatology of these affections, and chapters on intestinal indigestion, enteritis, dysentery, ulcers of the intestine, and intestinal neoplasms. Three chapters of the work have been written by associate pro. fessors in the University of Maryland. These deal prin. cipally with the more scientific, as apart from the clinical, aspect of the subject.

The section on the Anatomy and Histology of the Intestines is from the pen of J. Holmes Smith, M.D., associate professor of anatomy. The illustrations accompanying this part of the book are excellent and include those of many dissections which greatly help to explain the letterpress. The physiology of the intestines is well described and the chapter on the Utilisation of Food in the Stomach or Intes. tines of the Healthy Man and under Abnormal Conditions is well worthy of perusal.

Dr. Hemmeter's views on gastric digestion will require further corroboration before they are generally accepted. He believes that the digestive and absorptive capacity of the stomach has been much overrated. He claims that the stomach is nothing more than a reservoir to receive the food and practically to transmit it to the intestine, and that the digestive and absorptive processes which occur in the stomach itself are so insignificant that they may be practically disregarded. However, he does not give full details of his reasons for arriving at the above conclusion, since the present volume is concerned with the intestines and not with the stomach.

The chapter on Intestinal Bacteria is written by W. $R$. Stokes, M. D., associate professor of pathology and bacteriology in the University of Maryland. The author has performed his task admirably and has produced an interesting account of the principal micro-organisms which are known to be present under varying conditions in the intestine. Dr. Stokes evidently has a thorough knowledge of his subject and is able to express his views in very explicit terms. His account of the bacillus coli communis is very clear and accurate and contains a full summary of all that is at present known with regard to this organism.

Chapter IX. is written by Dr. H. Adler and is entitled, "Diagnostic Significance of Examination of Fæces and Urine." The macroscopic, microscopic, and chemical examinations of the stools are carefully described. Attention is drawn to the importance of examining the fæces in cases of faulty digestion, so that according to the nature of food matters undigested there may follow a proper selection and preparation of the diet. This point is only too frequently neglected and the digestive organs are loaded with materials of which they cannot make proper use, thus increasing rather than diminishing the digestive troubles from which the patient may be suffering.

Turning to the portion of the volume dealing with diet we find much that is interesting. After a discussion on the principles of dietetic treatment Dr. Hemmeter proceeds. to give general rules as to the diet which should be employed in certain forms of intestinal affections, such as dyspepsia 